\title{
Exhaled nitric oxide in interstitial lung diseases
}

\author{
P. Cameli*, E. Bargagli, R.M. Refini, M.G. Pieroni, D. Bennett, P. Rottoli \\ Department of Medical and Surgical Sciences and Neurosciences, Respiratory Disease and Lung Transplantation Section, Le Scotte Hospital, Siena, Italy
}

\section{A R T I C L E I N F O}

\section{Article history:}

Accepted 21 March 2014

Available online 2 April 2014

\section{Keywords:}

Nitric oxide

Idiopathic pulmonary fibrosis

Non-specific interstitial pneumonia

biomarker

Oxidative stress

Nitrosative stress

\begin{abstract}
A B S T R A C T
Nitric oxide (NO) is a biomarker of nitrosative stress, which is involved in the pathogenesis of idiopathic interstitial pneumonias (IIP). This study evaluates exhaled NO levels in IIP patients and relates alveolar concentrations of NO ( Calv $_{\mathrm{NO}}$ ) to pulmonary function test (PFT) and 6-minute walking test (6MWT) parameters. We measured fractional exhaled nitric oxide (FeNO), Calv $\mathrm{N}_{\mathrm{NO}}$ and maximum conducting airway wall flux (J'aw ${ }_{\mathrm{NO}}$ ) in 30 healthy subjects and 30 patients with IIP (22 idiopathic pulmonary fibrosis and 8 idiopathic non-specific interstitial pneumonias). IIP patients had higher FeNO at flow rates of $50-100-150 \mathrm{ml} / \mathrm{s}$ and higher Calv $\mathrm{NO}_{\mathrm{NO}}$ levels than healthy controls $(p<0.0001)$. Calv $\mathrm{NO}_{\mathrm{NO}}$ was significantly correlated with 6 -minute walking distance $(p<0.0001)$, recovery time $(p<0.0005)$, TLC $(p<0.001)$, FVC $(p=0.01)$ and TLCO $(p<0.01)$. IIP patients showed abnormal nitric oxide production, probably due to lung fibrosis and oxidative-mediated lung injury. Calv ${ }_{\mathrm{NO}}$ was correlated with PFT and 6MWT parameters and is proposed as a potential biomarker of lung fibrosis and exercise tolerance.
\end{abstract}

(C) 2014 Elsevier B.V. All rights reserved.

\section{Introduction}

Nitric oxide (NO) is a molecule produced by the human lungs and is present in exhaled breath. It plays a homeostatic role in a wide range of physiological processes. Since the early 1990s, systems for measuring NO in exhaled breath have been developed and used to measure the fraction of exhaled nitric oxide (FeNO) in many lung diseases, including asthma, chronic obstructive pulmonary disease (COPD), cystic fibrosis, primary ciliary dyskinesia and pulmonary arterial hypertension (American Thoracic Society European Respiratory Society, 2010). The anatomical origin of NO production can be separated using a two-compartment model of the lung (airway and alveolar compartments) and partitioning NO into alveolar concentration of exhaled NO (Calv $\left.{ }_{\mathrm{NO}}\right)$ and maximum conducting airway wall flux (J'aw ${ }_{\text {NO }}$ ) (Tsoukias and George, 1998). At pulmonary level, NO acts as a vasodilator, bronchodilator,

Abbreviations: NO, nitric oxide; eNO, exhaled nitric oxide; FeNO, fraction of exhaled NO; VeNO, exhaled NO output; Calv ${ }_{\mathrm{NO}}$, alveolar concentration of NO; J'aw $\mathrm{N}_{\mathrm{NO}}$, maximum conducting airway wall flux; IPF, idiopathic pulmonary fibrosis; BAL, bronchoalveolar lavage; NSIP, non-specific interstitial pneumonia; PFT, pulmonary function tests; 6MWT, 6-minute walking test; TLC, total lung capacity; FVC, forced vital capacity; TLCO, transfer factor of the lung for carbon monoxide; COPD, chronic obstructive pulmonary disease; IIP, idiopathic interstitial pneumonia; $2 \mathrm{CM}$, twocompartment model; TMAD, trumpet model of axial diffusion.

* Corresponding author. Tel.: +39 0577 586710/+39 3297 856833; fax: +390577 280744 .

E-mail address: paolocameli88@gmail.com (P. Cameli). neurotransmitter and inflammatory mediator. It is involved in several pathological conditions, including fibrogenesis and oxidative stress. NO is the principal reactive nitrogen species encountered in vivo, and at high concentrations causes toxicity by combining with superoxide anion to produce peroxynitrite. This molecule may cause nitration (addition of $-\mathrm{NO}_{2}$ ) of most classes of biological molecules, determining protein dysfunction, inhibition of mitochondrial respiration and DNA damage. Experimental studies support the role of oxidative and nitrosative stress in the pathogenesis of interstitial lung diseases (ILD), though few studies on exhaled NO analysis are available for idiopathic interstitial pneumonia (IIP) and particularly idiopathic pulmonary fibrosis (IPF) patients (Chapman et al., 2010; Chow et al., 2012; Hua-Huy et al., 2010; Moodley and Lalloo, 2001). In particular, Pullamssetti et al. (2011) noted a potential role of NO in IPF. IPF and idiopathic nonspecific interstitial pneumonia (NSIP) with fibrosing pattern are the most common idiopathic interstitial pneumonias: they are characterized by a poor prognosis (3-5 years survival for IPF), due to the chronic progressive restrictive functional impairment of the lung, caused by fibrotic degeneration of the lung parenchyma. In addition to that, IPF and NSIP patients early develop a severe impairment of physical tolerance, due to progressive hypoxemia, which seriously deteriorates their performance status and quality of life. In order to analyze this perspective in these patients, the use of 6-minute walking test (6MWT) has been already validated in IPF, because of its safety and its practicality: therefore, unlike maximal cardiopulmonary exercise testing, 6MWT can be performed by almost all patients and, because it is self-paced, is better tolerated and more 
reflective of daily activities than other functional tests: Mura et al. (2012) has demonstrated that 6 min walk distance at the time of diagnosis is a significant predictor of survival in IPF patients. The progress of these diseases is also unpredictable at the time of diagnosis, so the need for new severity biomarkers that can predict the natural history and the physical tolerance of these patients is intensely felt

Regarding other diffuse lung diseases, Tiev et al. (2012) reported increased production of alveolar nitric oxide associated with lung fibroblast proliferation in patients with pulmonary fibrosis associated with systemic sclerosis and proposed Calv $_{\mathrm{NO}}$ as a non-invasive biological marker of alveolitis predictive of deterioration of lung function. Evaluation of NO in exhaled breath condensates from patients with sarcoidosis (a multisystem granulomatous disease of unknown etiology, in which inflammation can play a fundamental physiopathological role, only evolving to diffuse pulmonary fibrosis in a minority of patients) has produced conflicting results. Moodley et al. (1999) reported higher concentrations of FeNO in exhaled breath samples from 12 patients with sarcoidosis than in controls, while Wilsher et al. (2005) described contrary findings in a cohort of 52 patients. Choi et al. (2009) failed to find any significant differences in FeNO concentrations between patients with sarcoidosis and healthy non-smoker controls, however they reported significant negative correlations between Calv $\mathrm{NO}_{\mathrm{NO}}$ and percentage values of forced vital capacity (FVC) and transfer factor of the lung for carbon monoxide (TLCO). The authors concluded by not recommending exhaled FeNO detection in routine clinical practice, due to the large inter-subject variability they found. Higher Calv ${ }_{\mathrm{NO}}$ levels have also been reported in pneumoconiosis patients than in controls, and exhaled NO has been proposed as a potential clinical biomarker of silica- and asbestos-exposed subjects susceptible to silicosis (Fubini and Hubbard, 2003; Sauni et al., 2012) and asbestosis (Lehtimäki et al., 2010).

As limited literature is available on exhaled NO levels in patients with idiopathic interstitial pneumonias (Furukawa et al., 2011; Schildge, 2011; Zhao et al., 2012), we designed the present study to compare exhaled FeNO concentrations of patients with idiopathic pulmonary fibrosis and non-specific interstitial pneumonia with those of a population of healthy sex- and age-matched controls, in order to contribute to the study of FeNO in IIP. Instead, to our knowledge, no literature is available on the effect of mild physical exercise in exhaled NO levels in IPF and NSIP patients. For this reason, to better characterize the pattern of NO in fibrotic patients, we also examined eNO parameters at rest and after the 6-minute walking test (6MWT) in relation to reduced physical tolerance (which influences quality of life and the reproducibility of lung function tests).

\section{Materials and methods}

\subsection{Study population and study design}

Thirty ILD patients were enrolled in the study that was performed at Siena Regional Referral Centre for Sarcoidosis and Interstitial Lung Diseases between September 2012 and May 2013. Twenty-two patients had idiopathic pulmonary fibrosis (17 males, mean age $64 \pm 10$ years), and eight patients had idiopathic nonspecific interstitial pneumonia with fibrosing pattern (2 males, mean age $63 \pm 9$ years). Diagnosis was performed according to international guidelines (Raghu et al., 2011) and all patients underwent pulmonary function tests (PFT), including single-breath diffusing capacity for carbon monoxide at diagnosis and almost every six months thereafter. An accurate medical history was obtained from all patients in order to evaluate professional exposure, smoking and medication history. Chest x-rays were taken in posterior-anterior and lateral projections. High resolution computed tomography of the chest was performed in all patients for diagnostic purposes. All patients and controls were asked to perform a complete 6-minute walking test (6MWT). Nine IPF patients were non-smokers and 13 were ex-smokers (mean packs/year $10.27 \pm 12.23$ ). Six NSIP patients were non-smokers and two NSIP patients were ex-smokers (mean packs/year $5.62 \pm 10.5$ ). The patients had no history of atopy, concomitant asthma, cancer or autoimmune disorders, and NSIP secondary to systemic sclerosis or rheumatoid arthritis was specifically excluded. At the moment of NO detection, patients with IPF and NSIP were in stable phase and had been free of respiratory infections and/or acute exacerbations for at least 4 weeks.

The control group included 30 healthy volunteers (16 male, mean age $62 \pm 4.73$ years), 15 non-smokers and 15 exsmokers (mean packs/year 5.25 \pm 7.2 ). Patients treated with phosphodiesterase-five inhibitors and ICS were excluded. All healthy volunteers had normal lung function and had suffered no respiratory symptoms or infections in the last 4 weeks. All patients and controls gave their written informed consent to the study, which was approved by the local ethics committee, and all portions of the study were performed according to the Declaration of Helsinki.

\subsection{Study protocol}

Participants were asked to avoid alcoholic drinks, coffee and other food or beverages containing caffeine (cola, tea, cocoa) for at least $3 \mathrm{~h}$ before the examination. They also had to abstain from foods containing nitrates (lettuce, spinach, cabbage, sausages) and high-fat foods for at least $12 \mathrm{~h}$ before the examination. Patients on bronchodilators had to suspend therapy $12 \mathrm{~h}$ before the test. All participants had a mouthwash with water just before the test. Baseline determination of systolic pressure, diastolic pressure, heart rate, pulsed arterial oxygen saturation and exhaled nitric oxide measurements were taken after $10 \mathrm{~min}$ of rest in a quiet and comfortable environment. All subjects then performed a complete 6MWT, after which exhaled nitric oxide measurements were repeated within $5 \mathrm{~min}$. IPF and NSIP patients also underwent PFT on the same day.

\subsection{Pulmonary function tests}

The following lung function measurements were recorded according to ATS/ERS standards (Miller et al., 2005), using a Jaeger Body Plethysmograph with corrections for temperature and barometric pressure: forced expiratory volume in the first second $\left(\mathrm{FEV}_{1}\right)$, forced vital capacity (FVC), FEV1/FVC, total lung capacity (TLC), residual volume (RV), carbon monoxide lung transfer factor $\left(T_{\mathrm{LCO}}\right)$ and capacity carbon monoxide lung transfer factor/alveolar volume $\left(T_{\mathrm{LCO}} / \mathrm{VA}\right)$. All parameters were expressed as percentages of predicted reference values. $T_{\mathrm{LCO}}$ measurement could not be performed in four patients who were on oxygen therapy. PFTs were performed at least $2 \mathrm{~h}$ after exhaled NO measurements.

\subsection{Six-minute walking test}

IPF and NSIP patients and controls performed the six-minute walking test according to the standards of the ATS/ERS guidelines (ATS Statement, 2002).

\subsection{Exhaled nitric oxide measurements}

Nitric oxide was measured using a chemiluminescence analyzer (model Hypair FeNO medisoft Cardioline Exp'air, 2010) according to ATS-ERS recommendations for online measurement of FeNO in adults (American Thoracic Society European Respiratory Society, 
Table 1

Demographic findings, clinical features, 6MWT parameters, lung function test parameters including TLCO in patients with IPF and NSIP patients compared than controls.

\begin{tabular}{|c|c|c|c|c|}
\hline Parameters & IPF & NSIP & Controls & $p$-Value \\
\hline No. & 22 & 8 & 30 & \\
\hline Age (aa) & $64.81 \pm 10.45$ & $63.25 \pm 9.48$ & $62 \pm 4.73$ & ns \\
\hline Male (n) & $17(59 \%)$ & $2(25 \%)$ & $16(51 \%)$ & ns \\
\hline $\operatorname{BMI}\left(\mathrm{kg} / \mathrm{m}^{2}\right)$ & $26.25 \pm 3.49$ & $27.65 \pm 2.51$ & $25.9 \pm 2.9$ & ns \\
\hline Tobacco use (pack/year) & $10.27 \pm 11.8$ & $5.62 \pm 10.5$ & $5.2 \pm 7.2$ & ns \\
\hline Systolic PA (mmHg) & $125 \pm 12.23$ & $123.75 \pm 10.26$ & $121.3 \pm 11.9$ & ns \\
\hline Diastolic PA (mmHg) & $73.18 \pm 10.86$ & $75 \pm 9.25$ & $72.6 \pm 9.8$ & ns \\
\hline Heart rate (bpm) & $78.95 \pm 11.63$ & $76.5 \pm 5.2$ & $73 \pm 9$ & ns \\
\hline $\mathrm{SpO}_{2} \%$ & $95.4 \pm 1.14$ & $95.7 \pm 2.3$ & $97.6 \pm 0.9$ & $\begin{array}{l}<0.001^{\dagger} \\
\quad 6 M W T\end{array}$ \\
\hline baseline $\mathrm{SpO}_{2} \%$ & $95.2 \pm 0.94$ & $95.87 \pm 1.88$ & $97.4 \pm 0.6$ & $<0.0001^{*}$ \\
\hline end test $\mathrm{SpO}_{2} \%$ & $89.63 \pm 2.92$ & $90.5 \pm 2.32$ & $96.5 \pm 1.8$ & $<0.0001^{*}$ \\
\hline baseline HR (bpm) & $77.5 \pm 8.4$ & $78.75 \pm 6.4$ & $71.9 \pm 8.4$ & $<0.0001^{*}$ \\
\hline post test HR (bpm) & $100.36 \pm 17.49$ & $100.87 \pm 12.11$ & $85 \pm 10.9$ & $<0.0001^{*}$ \\
\hline Walk distance $(\mathrm{m})$ & $297.72 \pm 55.02$ & $282.5 \pm 73.63$ & $366.8 \pm 39$ & $<0.0001^{*}$ \\
\hline $\mathrm{SpO}_{2}$ recovery time (s) & $110.9 \pm 59.19$ & $88.75 \pm 65.56$ & $7.6 \pm 11$ & $<0.0001^{*}$ \\
\hline Borg index baseline & $0.68 \pm 1.24$ & $0.75 \pm 1.48$ & 0 & $<0.0001^{*}$ \\
\hline Borg index post test & $4 \pm 2.37$ & $5.25 \pm 2.96$ & $0.4 \pm 0.8$ & $<0.0001^{*}$ \\
\hline \multicolumn{5}{|l|}{ PFT (\% reference values) } \\
\hline FVC $\%$ & $69.52 \pm 18.15$ & $77.71 \pm 25.51$ & & $\mathrm{~ns}^{\ddagger}$ \\
\hline $\mathrm{FEV}_{1} \%$ & $69.95 \pm 18.33$ & $76.81 \pm 25.82$ & & $\mathrm{~ns}^{\ddagger}$ \\
\hline $\mathrm{FEV}_{1} / \mathrm{FVC} \%$ & $78.22 \pm 9.44$ & $78.96 \pm 8.64$ & & $\mathrm{~ns}^{\ddagger}$ \\
\hline ITGV \% & $88 \pm 16.72$ & $91.31 \pm 26.52$ & & $\mathrm{~ns}^{\ddagger}$ \\
\hline RV \% & $92.51 \pm 18.06$ & $93.03 \pm 25.74$ & & $\mathrm{~ns}^{\ddagger}$ \\
\hline TLC $\%$ & $77.45 \pm 14.95$ & $76.47 \pm 16.36$ & & $\mathrm{~ns}^{\ddagger}$ \\
\hline RV/TLC & $48.29 \pm 8.19$ & $48.21 \pm 8.75$ & & $\mathrm{~ns}^{\ddagger}$ \\
\hline TLCO \% & $43.33 \pm 16.65$ & $41.06 \pm 21.25$ & & $\mathrm{~ns}^{\ddagger}$ \\
\hline TLCO/VA \% & $68.51 \pm 19.22$ & $59.81 \pm 11.07$ & & $\mathrm{~ns}^{\ddagger}$ \\
\hline
\end{tabular}

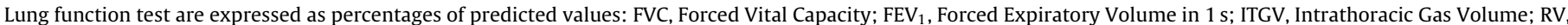
Residual Volume; TLC, Total Lung Capacity; TLCO, Transfer Factor of the Lung for Carbon Monoxide; VA, Alveolar Volume.

${ }^{*} p$-value between IIP (IPF and NSIP) patients and controls.

$\dagger p$-value between IPF and controls.

${ }^{\ddagger}$-value between IPF and NSIP patients.

2010). The analyzer was sensitive to NO from 1 to $500 \mathrm{ppb}$ with a resolution of $1 \mathrm{ppb}$. All measurements were undertaken at ambient NO levels of $<10 \mathrm{ppb}$. Subjects were studied in sitting position. Exhaled NO was measured during slow exhalation from total lung capacity against a positive pressure kept constantly between $5-20 \mathrm{~cm} \mathrm{H}_{2} \mathrm{O}$ to generate exhalation flow rates of 50, 100 and $150 \mathrm{ml} / \mathrm{s}$. The exhalation flow rate was kept as constant as possible using a biofeedback visual display. For each flow rate, at least two technically adequate measurements were performed. In order to evaluate NO concentration profile versus time during exhalation, we also measured exhaled NO output (VeNO) in patients and controls. A third measurement was performed if the difference between first two measurements was more than $10 \%$. The four patients on oxygen therapy were taken off it during exhaled nitric oxide measurements. The flow-independent NO parameters, Calv $\mathrm{NO}_{\mathrm{NO}}$ and J'aw $\mathrm{NO}_{\mathrm{NO}}$, were calculated using the Tsoukias two-compartment model of NO exchange (2CM; Tsoukias and George, 1998). Another analytical method to represent our results was the trumpet model of axial diffusion (TMAD) of Condorelli et al. (2007). A linear relationship between the three points (50, 100 and $150 \mathrm{ml} / \mathrm{s}$ ) of the NO flux against the flow was evaluated for each subject by a linearity test.

\subsection{Data collection and reproducibility}

Each measurement was considered acceptable with a confidence rate $>95 \%$ and a flow stability $>90 \%$. All measurements were made by a single investigator, guaranteeing inter- and intraobserver agreement.

\subsection{Statistical analysis}

Data was expressed as mean \pm standard deviation(SD). Comparisons between IPF, NSIP patients and controls were performed by
Mann-Whitney test. Changes in clinical and exhaled NO parameters observed after the 6MWT were compared using two-way ANOVA, with Bonferroni's post test. Correlations between Calv NO $_{\text {, }}$ PFT values and 6MWT parameters were made by Spearman's test. A $p$-value $<0.05$ was considered statistically significant. Statistical analyses were performed using Graph Pad Prism 5.

\section{Results}

\subsection{Clinical and functional characteristics}

Clinical and demographic data of patients with IPF and NSIP and controls are reported in Table 1, together with PFT results, including TLCO percentages, and 6MWT parameters. Globally, IIP patients showed mild to moderate restrictive impairment and 6MWT parameters (baseline and end test $\mathrm{SpO}_{2}$, heart rate, Borg index, 6-minute walking distance and recovery time) were significantly different from those measured in controls $(p<0.0001)$.

\section{2. eNO values in IPF and NSIP and healthy controls}

FeNO values at flow rates of 50,100 and $150 \mathrm{ml} / \mathrm{s}$ were significantly higher in IPF and NSIP patients than in healthy controls $(p<0.0001)$ (Fig. 1, Table 2). At baseline, flow-independent parameters included Calv $_{\mathrm{NO}}$, that was significantly higher in IPF and NSIP patients than controls $(p<0.0001)$, and J'aw ${ }_{\mathrm{NO}}$, which did not differ between the two groups $(p>0.05)$ (Table 2). These results were obtained applying the 2CM and TMAD. In Table 2, exhaled VeNO was also reported to evaluate NO concentration profile versus time during exhalation. VeNO values at flow rates of 50,100 and $150 \mathrm{ml} / \mathrm{s}$ were significantly higher in IPF and NSIP patients than healthy controls $(p<0.0001)$. FeNO $150(17.7 \pm 8.2$ vs $15.2 \pm 7 \mathrm{ppb} ; p>0.05)$ and 


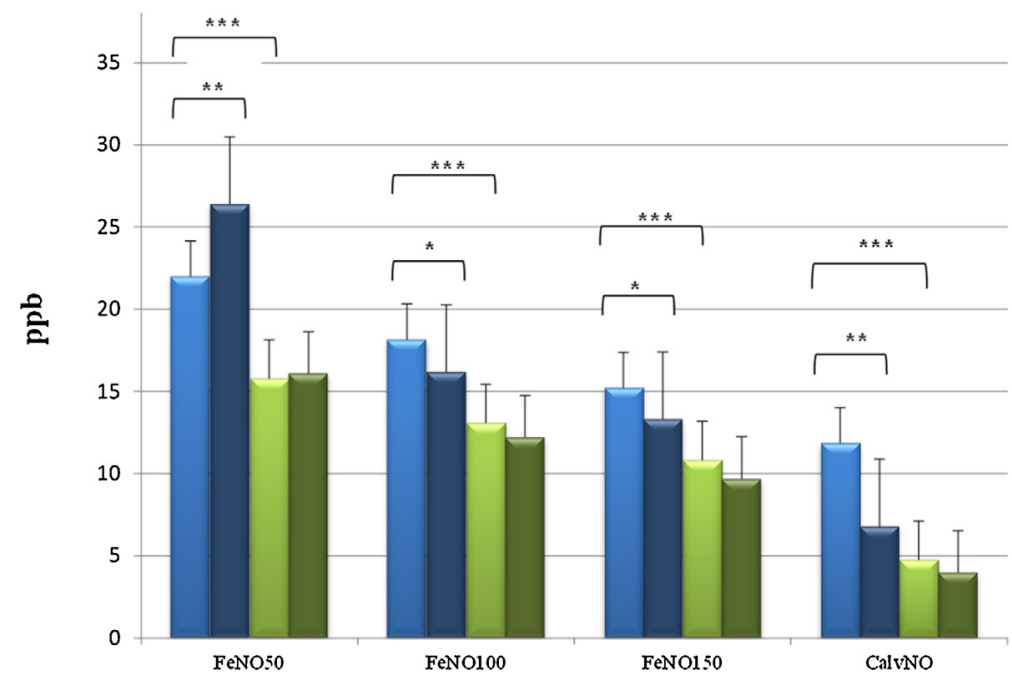

घIPF + NSIP baseline

- IPF + NSIP post GMVT

$\square$ Controls baseline

aControls post $6 \mathrm{MNVT}$

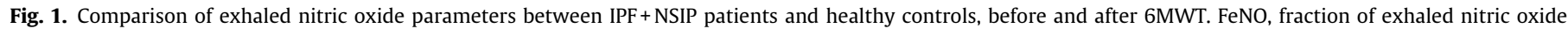

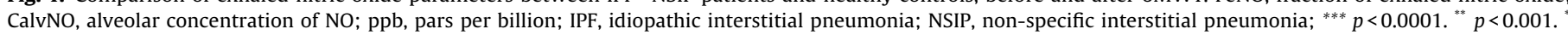
$p<0.05$.

VeNO $150(156 \pm 24.5$ vs $144.9 \pm 27.6 \mathrm{nl} / \mathrm{min} ; p>0.05)$ were not significantly different to IPF and NSIP patients while were significantly higher than healthy controls $(17.7 \pm 8.2$ vs $10.8 \pm 2.9 \mathrm{ppb}$; $156 \pm 24.5$ vs $95 \pm 10 \mathrm{nl} / \mathrm{min} ; p<0.01$ and $p<0.001$, respectively). There were no significant differences between non-smokers and ex-smokers in any population

\section{3. eNO values and 6MWT.}

After the 6MWT, FeNO 50 values $(p<0.001)$, VeNO 50 values $(p<0.0001)$ and J'awNO levels $(p<0.001)$ were significantly higher, and FeNO 100 values $(p<0.05)$, FeNO 150 values $(p<0.05)$, VeNO $100(p<0.05)$, VeNO 150 levels $(p<0.05)$ and CalvNO $(p<0.001)$ significantly lower, in IPF and NSIP patients with respect to before 6MWT (Figs. 1 and 2, Table 2). IPF and NSIP patients didn't significantly differ in any baseline or post 6MWT parameters. No significant changes were observed in healthy controls after 6MWT. In the patients group, baseline Calv NO $_{\text {O }}$ was significantly correlated with six-minute walking distance $(r=-0.73, p<0.0001)$, recovery time $(r=0.63 ; p<0.0005)$ and $\mathrm{SpO}_{2}$ post test $(r=-0.54 ; p<0.01)$. Calv $_{\text {NO }}$ was also inversely related to FVC $(r=-0.47 ; p<0.01)$, TLC $(r=-0.62 ; p<0.001)$ and TLCO percentages $(r=-0.60 ; p<0.01)$ (Fig. 3). No significant correlations were found between FeNO 50,

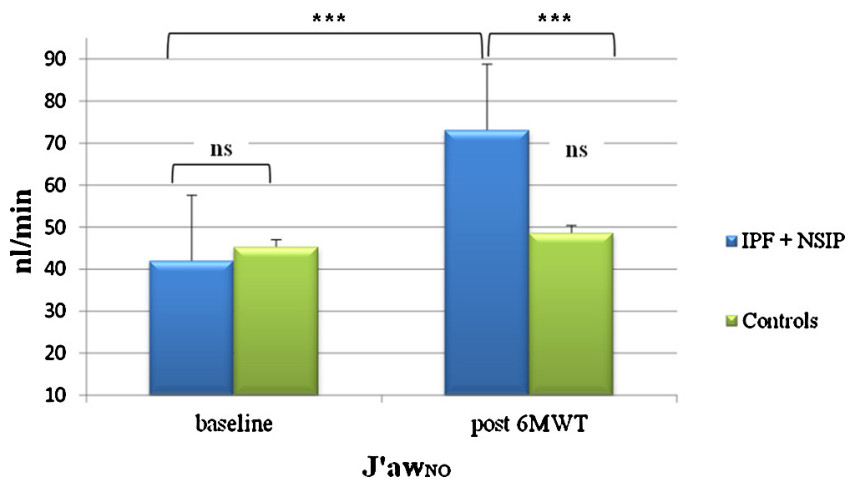

Fig. 2. Comparison of J'aw $w_{N O}$ at baseline and after 6MWT between patients and healthy controls. J'awNO did not significantly change in patients with respect to controls at baseline, whereas it was significantly higher in IIP patients than controls after 6MWT. J'awNO did not change in healthy subjects after 6MWT. J'awNo, maximum conducting airway wall flux; 6MWT, 6-minute walking test; IPF, idiopathic pulmonary fibrosis; NSIP, non-specific interstitial pneumonia; ${ }^{* * *} p<0.001$ in patients; ns: non significant.

Table 2

eNO parameters in IPF and NSIP patients and healthy controls.

\begin{tabular}{|c|c|c|c|c|c|c|c|}
\hline \multirow[t]{2}{*}{ eNo parameters } & \multicolumn{2}{|c|}{ IPF } & \multicolumn{2}{|c|}{ NSIP } & \multicolumn{2}{|l|}{ Controls } & \multirow[t]{2}{*}{$p$-Value } \\
\hline & Baseline & Post 6MWT & Baseline & Post 6MWT & Baseline & Post 6MWT & \\
\hline FeNO 50 ml/s (ppb) & $22.3 \pm 8.4$ & $26.1 \pm 10.5^{\dagger}$ & $21 \pm 8$ & $27.3 \pm 11.2^{\ddagger}$ & $15.8 \pm 4.1$ & $16.1 \pm 4.1$ & $<0.0001^{*}$ \\
\hline FeNO $100 \mathrm{ml} / \mathrm{s}(\mathrm{ppb})$ & $18.2 \pm 6.8$ & $16.1 \pm 6.8^{\dagger}$ & $17.8 \pm 5.3$ & $16.6 \pm 6.4$ & $13.1 \pm 2.8$ & $12.2 \pm 3.5$ & $<0.0001^{*}$ \\
\hline FeNO $150 \mathrm{ml} / \mathrm{s}(\mathrm{ppb})$ & $15.2 \pm 7.7$ & $13.2 \pm 5.5^{\dagger}$ & $15.1 \pm 5.1$ & $13.6 \pm 4.6$ & $10.8 \pm 2.9$ & $9.7 \pm 2.4$ & $<0.0001^{*}$ \\
\hline $\mathrm{J}^{\prime} \mathrm{w}_{\mathrm{NO}}(\mathrm{nl} / \mathrm{min})^{\mathrm{a}}$ & $42.6 \pm 24.6$ & $69.5 \pm 37.1^{\dagger}$ & $40.3 \pm 30.9$ & $83.2 \pm 71.3$ & $45.3 \pm 22.3$ & $48.7 \pm 20.5$ & ns \\
\hline Calv $_{\mathrm{NO}}(\mathrm{ppb})^{\mathrm{a}}$ & $11.5 \pm 6.6$ & $7 \pm 3.8^{\dagger}$ & $12.6 \pm 6.8$ & $6.7 \pm 3.2^{\ddagger}$ & $4.7 \pm 2.3$ & $3.9 \pm 1.6$ & $<0.0001^{*}$ \\
\hline $\mathrm{J}^{\prime} \mathrm{aw}_{\mathrm{NO}}(\mathrm{nl} / \mathrm{min})^{\mathrm{b}}$ & $71.4 \pm 44$ & $124 \pm 81^{\dagger}$ & $67.6 \pm 49.2$ & $135.6 \pm 114$ & $77.1 \pm 38$ & $82.8 \pm 35$ & Ns \\
\hline Calv $_{\text {NO }}(\mathrm{ppb})^{\mathrm{b}}$ & $10.7 \pm 5.9$ & $6.2 \pm 3.3^{\dagger}$ & $11.2 \pm 5.7$ & $6.1 \pm 2.7$ & $4.3 \pm 2.08$ & $3.6 \pm 1.4$ & $<0.0001^{*}$ \\
\hline VeNO $50 \mathrm{ml} / \mathrm{s}(\mathrm{nl} / \mathrm{min})$ & $81.8 \pm 18.4$ & $94.6 \pm 22.5^{\dagger}$ & $78.3 \pm 24$ & $100.5 \pm 32^{\ddagger}$ & $47.7 \pm 10.4$ & $51.5 \pm 8.4$ & $<0.0001^{*}$ \\
\hline VeNO $100 \mathrm{ml} / \mathrm{s}(\mathrm{nl} / \mathrm{min})$ & $115 \pm 25$ & $105 \pm 21^{\dagger}$ & $104 \pm 30$ & $118 \pm 45$ & $82.5 \pm 12$ & $84.2 \pm 9$ & $<0.0001^{*}$ \\
\hline VeNO $150 \mathrm{ml} / \mathrm{s}(\mathrm{nl} / \mathrm{min})$ & $149 \pm 27$ & $132 \pm 18^{\dagger}$ & $144 \pm 32$ & $137 \pm 34$ & $95 \pm 10$ & $99 \pm 7$ & $<0.0001^{*}$ \\
\hline
\end{tabular}

FeNO, fractional of exhaled nitric oxide; Calv $\mathrm{NO}_{\mathrm{N}}$, alveolar concentration of nitric oxide; J'aw $\mathrm{N}_{\mathrm{NO}}$, maximum conducting airway wall flux.

* $p$-value between IIP (IPF and NSIP) patients and controls.

$p<0.05$ with baseline IPF.

$\ddagger p<0.05$ with baseline NSIP.

a Two-compartment model by Tsoukias and George.

b Model of trumpet shape of the airway tree and axial diffusion by Condorelli et al. (2007). 
$100,150, J^{\prime} \mathrm{w}_{\mathrm{NO}}$ and six-minute walking distance, recovery time, FVC, TLC and TLCO.

\section{Discussion}

The present study evaluated exhaled nitric oxide parameters in IPF and NSIP patients, compared with a group of healthy subjects, demonstrating an increase at rest in FeNO at flow rates of 50, 100 and $150 \mathrm{ml} / \mathrm{s}$ and an increase in Calv $\mathrm{NO}_{\mathrm{N}}$ in IPF and NSIP patients compared with healthy controls.

Very little data is available on FeNO concentrations in exhaled breath of patients with IPF and NSIP (Furukawa et al., 2011; Schildge, 2011; Zhao et al., 2012), which prompted us to explore NO pattern in these diseases, considering the potential implications of $\mathrm{NO}$ as a mediator in the pathogenesis of pulmonary fibrosis. We also compared eNO values at rest and after exercise in our population as a contribution to the analysis of exercise-induced effects on eNO concentrations in IIP patients, as no literature is available on this topic and these patients soon develop low physical tolerance (which impairs quality of life and the reproducibility of PFT). Physical exercise is a crucial trigger of desaturation in IPF and NSIP patients and we decided to establish its effect on NO kinetics.

\subsection{NO and pulmonary fibrosis}

The increase in eNO parameters in our IIP patients can be explained not only by a reduced gas diffusion through a thickened alveolar-capillary membrane, but also by overexpression of inducible nitric oxide synthase (iNOS) and consequently higher production of NO in the lung parenchyma (Pullamsetti et al., 2011). The observation that NO is implicated in pulmonary fibrogenesis is demonstrated by studies reporting abnormal NO and derivative concentrations in BAL of murine fibrotic lungs (Jang et al., 2004; Wells et al., 2009) and BAL fluid of IPF patients Pullamsetti et al., 2011) as a result of overexpression of dimethylarginine dimethylaminohydrolases (DDAH) by type II pneumocytes. Our study strongly supports these findings indicating potential involvement of NO and derivates in the pathogenesis of interstitial lung diseases.

\subsection{NO and oxidative/nitrosative stress}

Another potential pathogenic role of NO in interstitial lung disease pathogenesis is NO involvement in oxidation-mediated lung damage (a function reported since the early 2000s). FeNO has been proposed as a biomarker of oxidative stress in other fibrotic diffuse lung diseases, including bleomycin-induced pulmonary fibrosis, systemic sclerosis and pneumoconiosis (Fubini and Hubbard, 2003; Inghilleri et al., 2006; Sauni et al., 2012; Tiev et al., 2012), while there have been few studies on the role of FeNO in oxidative-stressmediated lung fibrotic injury in IPF and NSIP. As many authors consider nitric oxide an essential molecule in the modulation of oxidant-antioxidant balance (Allen et al., 2009; Lanzetti et al., 2012; Rahman et al., 2006), the increase we found in our IIP patients is of interest.

Literature sustaining a possible role of NO in the oxidative and nitrosative stress that occurs in diffuse lung diseases forms the background of the present study. We demonstrated higher alveolar concentrations of NO in IIP patients than in controls and an inverse correlation between Calv $\mathrm{NO}_{\mathrm{N}}$ and lung function test parameters, suggesting that respiratory impairment was associated with higher NO concentrations.

Comparing IPF and NSIP patients with an asthmatic population, whereof more is known about eNO levels in the literature, it can

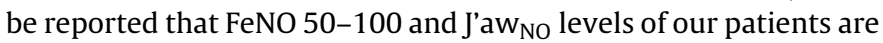
in general lower than in asthmatic patients. The increase of FeNO and of the maximum flux of NO in the airways regarding asthma has been already explored in many manuscripts (Chládková et al., 2012; Lehtimäki et al., 2001; Spears et al., 2011): the difference between asthmatic and IIP patients could be explained by distinctive pathogenetic pathways: in particular, elevated FeNO values in asthma is justified by the presence of eosinophilic inflammation in the airways, which is not commonly observed in IPF and NSIP patients.

\subsection{NO and lung function tests}

In our study we analyzed exhaled NO concentrations in patients and controls according to two different analytic models. The 2CM is a simple and attractive way to calculate Calv $_{\mathrm{NO}}$ and $\mathrm{J}^{\prime} \mathrm{aw} \mathrm{w}_{\mathrm{NO}}$. Since it probably does not represent the heterogeneity of alveolar compartments of IPF and NSIP, we also applied Condorelli's trumpet model of axial diffusion (TMAD) that considers increasing airway cross-section with distance into the airway tree and gasphase axial diffusion of NO, both critical aspects of NO exchange. The significant difference in Calv $_{\mathrm{NO}}$ between patients and controls was confirmed by both models, suggesting the importance of this parameter, recently proposed as a non-invasive biomarker of alveolitis, predictive of deterioration of lung function (Tiev et al., 2012). At the same time, reduced gas diffusion may partially influence the increase in Calv NO $_{\text {O }}$ by reducing the removal of alveolar NO across the thickened alveolar-capillary membrane. Interestingly, in a recent manuscript, in which NO measurements were compared in different ILD populations, Schildge added airway diffusing capacity of NO (DAWNO) to evaluate reduced NO diffusion from alveoli to the blood due to thickening of alveolar membranes. In our specific population, TLCO was mildly to severely reduced: of

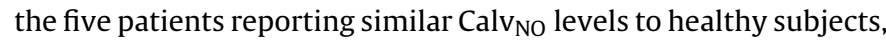
only two showed mild TLCO impairment (Fig. 3), suggesting that increased Calv $\mathrm{NO}_{\mathrm{NO}}$ may not only be due to a lower elimination rate but also to higher local production (Pullamssetti et al., 2011). Tiev et al. (2013) obtained similar results to ours in a very recent study of a population of patients with pulmonary fibrosis associated with systemic sclerosis, in whom increased Calv $\mathrm{NO}_{\mathrm{NO}}$ in exhaled breath was associated with severe reduction in TLC and TLCO. Although FeNO at $50 \mathrm{ml} / \mathrm{s}$ is recognized as a central airways parameter, its elevation in IPF patients has also been reported by Guilleminault et al. (2013), with values comparable to ours, suggesting that elevated alveolar concentrations of NO could drive the increased levels measured at all flow rates.

Since earlier airway closure is a possibility in IPF and NSIP patients, analysis of VeNO was added to obtain NO concentration profiles during exhalation. VeNO values were closely correlated with FeNO values for all flow rates in patients and controls, indicating the absence of airway closure, which therefore could not alter the interpretation of the results in patients with diffuse lung diseases. One limitation of this study is the lack of the evaluation of parallel inhomogeneity of lung parenchyma in IPF and NSIP: unfortunately, there are no experimental models in the literature that could help us standardize eNO values for different lung areas. Further research could be useful to create a new model for evaluation of eNO values in patients with interstitial lung diseases.

Our results therefore indicate Calv $_{\mathrm{NO}}$ as a potential biomarker of disease severity, also on the basis of the inverse correlations observed with $\mathrm{T}_{\mathrm{LCO}}$ percentages, 6-minute walking distance and end test $\mathrm{SpO}_{2}$, as well as evidence of a direct relationship with

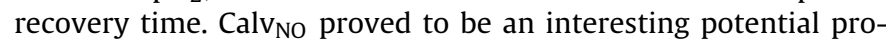
gnostic parameter worthy of further study, as suggested by Tiev in pulmonary fibrosis associated with systemic sclerosis, correlating with well-known clinical prognostic bioindicators, such as $\mathrm{T}_{\mathrm{LCO}}$, FVC and 6-minute walking distance. This parameter could be helpful in hypoxemic patients who cannot perform TLCO due to oxygen 

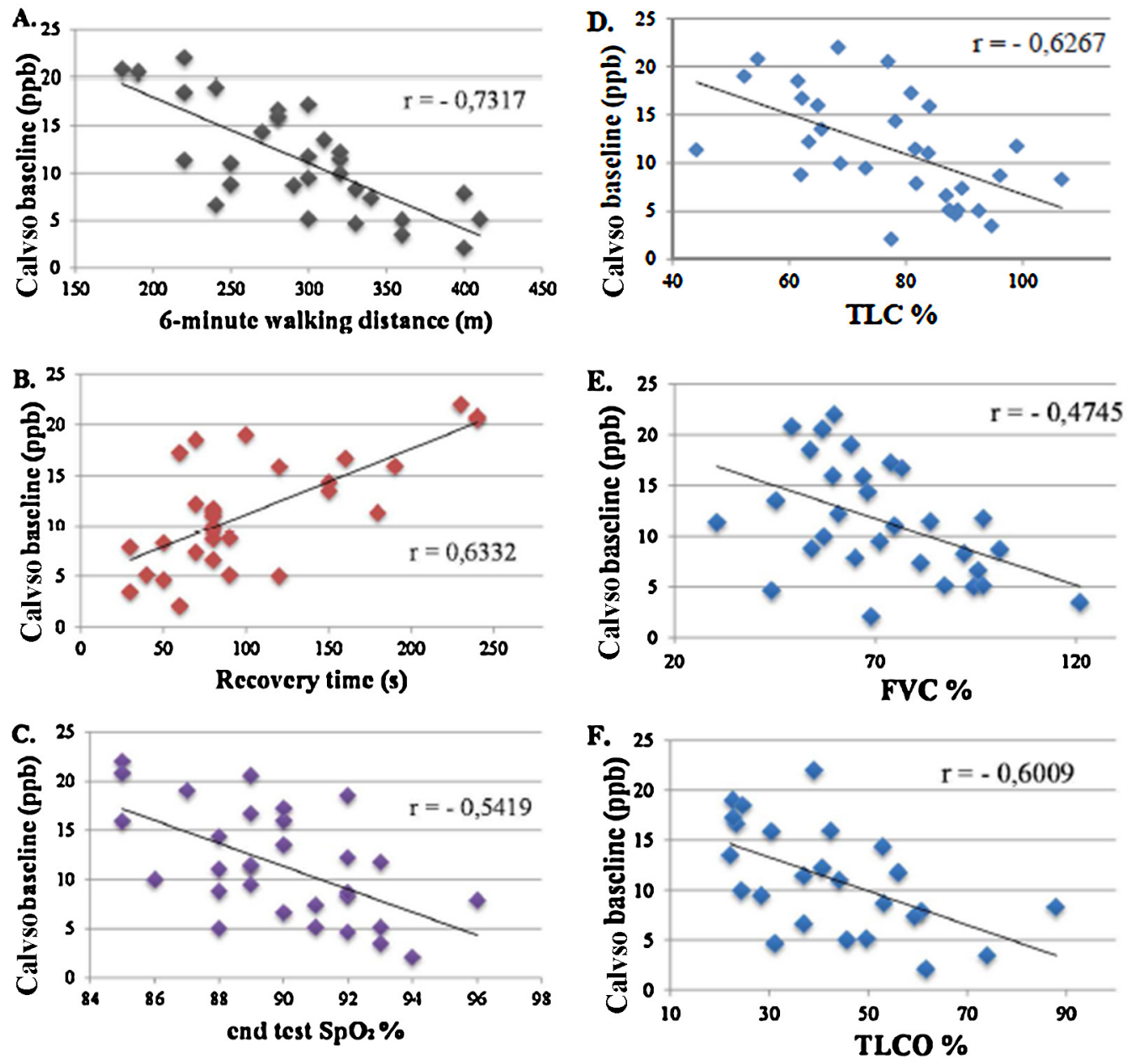

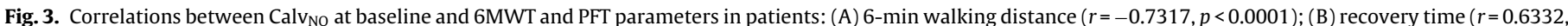

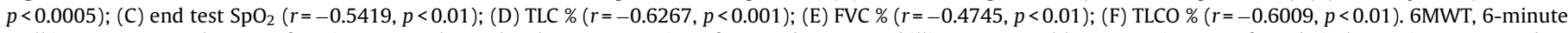

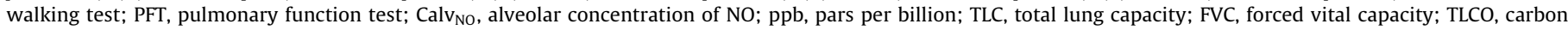
monoxide lung transfer factor.

therapy (Macintyre et al., 2005). Moreover, the procedure is less hard to perform than TLCO detection.

\subsection{NO and 6-minute walking test}

In our study, exercise-induced variations in airway and alveolar exhaled NO parameters were examined for the first time, revealing significantly different patterns. After the 6MWT, FeNO 50 values $(p<0.001)$ and J'aw ${ }_{\text {NO }}$ levels $(p<0.001)$ were significantly higher, and FeNO 100 values ( $p<0.05)$, FeNO 150 values $(p<0.05)$ and Calv NO $(p<0.001)$ significantly lower in IPF and NSIP patients than before 6MWT. Physical exertion presumably affected these parameters because it causes changes in ventilation in IIP patients, favouring clearance of $\mathrm{NO}$ from the alveoles and increasing the airway flux of NO. Hypoxemia caused by physical exertion may also induce lung changes that increase oxidant-antioxidant imbalance, affecting NO concentrations. Very little data is available on exercise-induced NO concentrations, particularly in IIP patients. Most relates to studies in asthma patients and healthy controls (Barreto et al., 2013; Therminarias et al., 1998). However, our study does not explain the physiopathogenetic causes of these modifications which are worthy of further investigations for a new interesting scenario.

In conclusion, our data shows higher levels of exhaled nitric oxide in patients with idiopathic interstitial pneumonia, probably due to oxidative/nitrosative stress related to pulmonary fibrosis. Alveolar concentrations of NO may be proposed as a marker of severity in pulmonary fibrosis since they were mainly elevated in IPF and NSIP patients with severe restrictive deficit and altered 6MWT. The present results also highlight the potential interest of this non-invasive and reproducible method as an additional parameter for lung functional assessment in diffuse lung diseases like IPF and NSIP.

The study was conducted at the Department of Medical and Surgical Sciences and Neurosciences, Respiratory Disease and Lung Transplantation Section; no funding sponsors to declare.

\section{Appendix A. Supplementary data}

Supplementary data associated with this article can be found, in the online version, at http://dx.doi.org/10.1016/j.resp.2014.03.011.

\section{References}

Allen, B.W., Demchenko, I.T., Piantadosi, C.A., 2009. Two faces of nitric oxide: implications for cellular mechanisms of oxygen toxicity. J. Appl. Physiol. 106 (2), 662-667.

American Thoracic Society; European Respiratory Society, 2010. ATS ERS recommendations for standardized procedures for the online and offline measurement of exhaled lower respiratory nitric oxide and nasal nitric oxide, 2005. Am. J. Respir. Crit. Care Med. 171, 912-930. 
ATS statement, 2002. Guidelines for the six-minute walk test. ATS Committee on Proficiency Standards for Clinical Pulmonary Function Laboratories. Am. J. Respir. Crit. Care Med. 166 (1), 111-117.

Barreto, M., Zambardi, R., Villa, M.P., 2013. Exhaled nitric oxide and other exhaled biomarkers in bronchial challenge with exercise in asthmatic children: current knowledge. Paediatr. Respir. Rev., pii: S1526-0542(13)00148-6.

Chapman, E.A., Thomas, P.S., Yates, D.H., 2010. Breath analysis in asbestos-related disorders: a review of the literature and potential future applications. J. Breath Res. 4 (3), 034001

Chládková, J., Senkerík, M., Havlínová, Z., Krcmová, I., Chládek, J., 2012 Nov. Alveolar concentration and bronchial flux of nitric oxide: two linear modeling methods evaluated in children and adolescents with allergic rhinitis and atopic asthma. Pediatr. Pulmonol. 47 (11), 1070-1079.

Choi, J., Hoffman, L.A., Sethi, J.M., Zullo, T.G., Gibson, K.F., 2009. Multiple flow rate measurement of exhaled nitric oxide in patients with sarcoidosis: a pilot feasibility study. Sarcoidosis Vasc. Diffuse Lung Dis. 26 (2), 98-109.

Chow, S., Thomas, P.S., Malouf, M., Yates, D.H., 2012. Exhaled breath condensate (EBC) biomarkers in pulmonary fibrosis. J. Breath Res. 6 (1) 016004.

Condorelli, P., Shin, H.W., Aledia, A.S., Silkoff, P.E., George, S.C., 2007. A simple technique to characterize proximal and peripheral nitric oxide exchange using constant flow exhalations and an axial diffusion model. J. Appl. Physiol. 102 (1), 417-425, Epub 2006 Aug 3.

Fubini, B., Hubbard, A., 2003. Reactive oxygen species (ROS) and reactive nitrogen species (RNS) generation by silica in inflammation and fibrosis. Free Radic. Biol. Med. 34 (12), 1507-1516.

Furukawa, K., Sugiura, H., Matsunaga, K., Ichikawa, T., Koarai, A., Hirano, T., Yanagisawa, S., Minakata, Y., Akamatsu, K., Kanda, M., Nishigai, M., Ichinose, M., 2011. Increase of nitrosative stress in patients with eosinophilic pneumonia. Respir. Res. $12,81$.

Guilleminault, L., Saint-Hilaire, A., Favelle, O., Caille, A., Boissinot, E., Henriet, A.C., Diot, P., Marchand-Adam, S., 2013. Can exhaled nitric oxide differentiate causes of pulmonary fibrosis? Respir. Med., pii: S0954-6111(13)00260-6.

Hua-Huy, T., Tiev, K.P., Chéreau, C., Duong-Quy, S., Cabane, J., Dinh-Xuan, A.T., 2010. Increased alveolar concentration of nitric oxide is related to serum-induced lung fibroblast proliferation in patients with systemic sclerosis. J. Rheumatol. 37 (8), 1680-1687.

Inghilleri, S., Morbini, P., Oggionni, T., Barni, S., Fenoglio, C., 2006. In situ assessment of oxidant and nitrogenic stress in bleomycin pulmonary fibrosis. Histochem. Cell Biol. 125 (6), 661-669.

Jang, A.S., Lee, J.U., Choi, I.S., Park, K.O., Lee, J.H., Park, S.W., Park, C.S., 2004. Expression of nitric oxide synthase, aquaporin 1 and aquaporin 5 in rat after bleomycin inhalation. Intensive Care Med. 30, 489-495.

Lanzetti, M., da Costa, C.A., Nesi, R.T., Barroso, M.V., Martins, V., Victoni, T., Lagente, V., Pires, K.M., e Silva, P.M., Resende, A.C., Porto, L.C., Benjamim, C.F., Valença, S.S., 2012. Oxidative stress and nitrosative stress are involved in different stages of proteolytic pulmonary emphysema. Free Radic. Biol. Med. 53 (11), 1993-2001.

Lehtimäki, L., Kankaanranta, H., Saarelainen, S., Hahtola, P., Järvenpää, R., Koivula, T., Turjanmaa, V., Moilanen, E., 2001 Jun. Extended exhaled NO measurement differentiates between alveolar and bronchial inflammation. Am. J. Respir. Crit. Care Med. 163 (7), 1557-1561.

Lehtimäki, L., Oksa, P., Järvenpää, R., Vierikko, T., Nieminen, R., Kankaanranta, H., Uitti, J., Moilanen, E., 2010. Inflammation in asbestos-exposed subjects with borderline parenchymal changes on HRCT. Respir. Med. 104 (7), 10421049.

Macintyre, N., Crapo, R.O., Viegi, G., Johnson, D.C., van der Grinten, C.P., Brusasco, V., Burgos, F., Casaburi, R., Coates, A., Enright, P., Gustafsson, P., Hankinson, J., Jensen, R., McKay, R., Miller, M.R., Navajas, D., Pedersen, O.F., Pellegrino, R., Wanger, J., 2005 Oct. Standardisation of the single-breath determination of carbon monoxide uptake in the lung. Eur. Respir. J. 26 (4), 720-735.
Miller, M.R., Crapo, R., Hankinson, J., Brusasco, V., Burgos, F., Casaburi, R., Coates, A Enright, P., van der Grinten, C.P., Gustafsson, P., Jensen, R., Johnson, D.C., MacIntyre, N., McKay, R., Navajas, D., Pedersen, O.F., Pellegrino, R., Viegi, G., Wanger, J., ATS/ERS Task Force., 2005. General considerations for lung function testing. Eur. Respir. J. 26 (1), 153-161.

Moodley, Y.P., Chetty, R., Lalloo, U.G., 1999. Nitric oxide levels in exhaled air and inducible nitric oxide synthase immunolocalization in pulmonary sarcoidosis. Eur. Respir. J. 14 (4), 822-827.

Moodley, Y.P., Lalloo, U.G., 2001. Exhaled nitric oxide is elevated in patients with progressive systemic sclerosis without interstitial lung disease. Chest 119 (5), 1449-1454.

Mura, M., Porretta, M.A., Bargagli, E., Sergiacomi, G., Zompatori, M., Sverzellati, N., Taglieri, A., Mezzasalma, F., Rottoli, P., Saltini, C., Rogliani, P., 2012 Jul. Predicting survival in newly diagnosed idiopathic pulmonary fibrosis: a 3-year prospective study. Eur. Respir. J. 40 (1), 101-109.

Pullamsetti, S.S., Savai, R., Dumitrascu, R., Dahal, B.K., Wilhelm, J., Konigshoff, M., Zakrzewicz, D., Ghofrani, H.A., Weissmann, N., Eickelberg, O., Guenther, A. Leiper, J., Seeger, W., Grimminger, F., Schermuly, R.T., 2011. The role of dimethylarginine dimethylaminohydrolase in idiopathic pulmonary fibrosis. Sci. Transl. Med. 3 (87), 87ra53.

Raghu, G., Collard, H.R., Egan, J.J., Martinez, F.J., Behr, J., Brown, K.K., Colby, T.V. Cordier, J.F., Flaherty, K.R., Lasky, J.A., Lynch, D.A., Ryu, J.H., Swigris, J.J., Wells, A.U., Ancochea, J., Bouros, D., Carvalho, C., Costabel, U., Ebina, M., Hansell, D.M., Johkoh, T., Kim, D.S., King Jr., T.E., Kondoh, Y., Myers, J., Müller, N.L., Nicholson, A.G., Richeldi, L., Selman, M., Dudden, R.F., Griss, B.S., Protzko, S.L., Schünemann, H.J., ATS/ERS/JRS/ALAT Committee on Idiopathic Pulmonary Fibrosis. 2011. Idiopathic pulmonary fibrosis: evidence-based guidelines for diagnosis and management. Am. J. Respir. Crit. Care Med. 183 (6), 788-824.

Rahman, I., Biswas, S.K., Kode, A., 2006. Oxidant and antioxidant balance in the airways and airway diseases. Eur. J. Pharmacol. 533 (1-3), 222-239.

Sauni, R., Oksa, P., Lehtimäki, L., Toivio, P., Palmroos, P., Nieminen, R., Moilanen, E. Uitti, J., 2012. Increased alveolar nitric oxide and systemic inflammation markers in silica-exposed workers. Occup. Environ. Med. 69 (4), 256-260.

Schildge, J., 2011 Mar. Stickstoffmonoxyd in der Atemluft von Patienten mit interstitiellen Lungenkrankheiten (Nitric oxide in exhaled breath of patients with interstitial lung diseases). Pneumologie 65 (3), 143-148.

Spears, M., Weir, C.J., Smith, A.D., McSharry, C., Chaudhuri, R., Johnson, M., Cameron, E., Thomson, N.C., 2011 Dec. Bronchial nitric oxide flux (J'aw) is sensitive to oral corticosteroids in smokers with asthma. Respir. Med. 105 (12), 1823-1830.

Therminarias, A., Oddou, M.F., Favre-Juvin, A., Flore, P., Delaire, M., 1998. Bronchia obstruction and exhaled nitric oxide response during exercise in cold air. Eur. Respir. J. 12 (5), 1040-1045.

Tiev, K.P., Hua-Huy, T., Kettaneh, A., Allanore, Y., Le-Dong, N.N., Duong-Quy, S. Cabane, J., Dinh-Xuan, A.T., 2012. Alveolar concentration of nitric oxide predicts pulmonary function deterioration in scleroderma. Thorax 67 (2), 157-163.

Tiev, K.P., Hua-Huy, T., Rivière, S., Le-Dong, N.N., Febvre, M., Cabane, J., Dinh-Xuan, A.T., 2013 Jan 15. High alveolar concentration of nitric oxide is associated with alveolitis in scleroderma. Nitric Oxide 28, 65-70 http://dx.doi.org/10.1016/j.niox.2012.10.005. Epub 2012 Oct 23.

Tsoukias, N.M., George, S.C., 1998. A two-compartment model of pulmonary nitric oxide exchange dynamics. J. Appl. Physiol. 85, 653-666.

Wells, S.M., Buford, M.C., Migliaccio, C.T., Holian, A., 2009. Elevated asymmetric dimethylarginine alters lung function and induces collagen deposition in mice. Am. J. Respir. Cell. Mol. Biol. 40, 179-188.

Wilsher, M., Fergusson, W., Milne, D., Wells, A.U., 2005. Exhaled nitric oxide in sarcoidosis. Thorax 60 (11), 967-970.

Zhao, Y., Cui, A., Wang, F., Wang, X.J., Chen, X., Jin, M.L., Huang, K.W., 2012. Characteristics of pulmonary inflammation in combined pulmonary fibrosis and emphysema. Chin. Med. J. (Engl) 125 (17), 3015-3021. 